\title{
Travelling towards and from minor islands through non-conventional air transport: demand and cost analysis
}

\author{
L. La Franca, M. Catalano, F. Castelluccio \& F. Montano \\ Department of Transportation Engineering, Palermo University, Italy
}

\begin{abstract}
This research addresses the role of innovative forms of passenger air transport in favouring the mobility of tourists visiting minor islands. In particular, we studied the feasibility of scheduled transport services using a helicopter and a seaplane for rapidly connecting Sicily in the south of Italy to the near and very attractive Eolie Islands.

In order to estimate the potential service demand, we allowed for the number of tourists arriving in the Eolie Archipelago during the period 1999-2008. In detail, we considered only the market of visitors with a high willingness-to-pay for time savings (individuals choosing superior hotels) coming from origins at least $300 \mathrm{~km}$ away from the Eolie Islands. Furthermore, we excluded a quota of travellers not disposed to flying, determined on the basis of a previous study about air transport demand. We also considered as potential users of the proposed transport services a percentage of the Eolie Isles' population that was set according to a recent study about the use of air transport by Sicilian residents. The resulting observations were employed to estimate forecasts through an ARIMA model.

After a technical analysis to identify the types of helicopter and seaplane suited to implementing regular transport services, we performed a cost analysis concerning the proposed non-conventional air transport services (taking into account fixed, variable, trading and financial costs). In particular, based on the ARIMA model demand forecasts, we determined the service supply (daily frequency and number of aircrafts) in the different cases and evaluated the related total cost per passenger.

At the final step, we compared the helicopter and seaplane options with the various existing transport alternatives that can be used to get to the Eolie Islands
\end{abstract}


from the major regional airport, according to generalized transport cost (calculated by adding the value of transit time, external costs and service fare). We found out that according to the generalized cost criterion, the helicopter is the best solution to connect the main Sicilian airport to the Eolie Isles.

Keywords: helicopter transport, seaplane transport, tourist trips, minor islands, scheduled transport service.

\section{Introduction}

This paper describes a research to study the role of innovative forms of passenger air transport in favouring mobility of tourists visiting minor islands. In particular, our work focuses on the Sicilian region, in the south of Italy: our aim is to investigate the feasibility of regular transport services for connecting Sicily to the near and very attractive Eolie Islands by helicopter and seaplane.

At present, most tourists going to one of the Eolie Islands have to reach Sicily by air and then use a combination of various modes of transport to get to their final destination. As an alternative, the two major regional airports of Catania and Palermo provide non-conventional air transport services on demand. In detail, some private companies (Icarus and Air Panarea), which obtained the certification for passenger transport by the National Civil Aviation Agency (ENAC), supply on demand helicopter transport services connecting the airport of Catania, on the eastern side of Sicily, to the Eolie Islands. Moreover, other private companies (AquaAirlines and Ermes) also provided with the certification by ENAC, operate transport services by charter seaplanes to connect the airport of Palermo, in the north of Sicily, to the Eolie Islands.

The air transport services illustrated above are characterized by low travel times but also by high operational costs and consequently fares. On one hand, as regards the helicopter-based transport, the employed types of aircraft employed can transfer only 4 passengers per trip, with the consequence of a high transport cost per user. On the other hand, though a seaplane can carry even 14 passengers per trip, the possibility of travelling by a seaplane depends upon the conditions of the sea which could make landing operations risky.

Considering the above, we investigated the feasibility of innovative nonconventional air transport line services as an alternative to the current transport system linking Sicily to the Eolie Islands. In particular, we compared the existing combinations of transport modes for reaching the Eolie Isles from the airport of Catania with the following options: regular transport services based on helicopters with high capacity (10-15 seats) and scheduled services based on seaplanes.

This paper in section 2 presents statistical data on tourism at the Eolie Islands followed by a description in section 3 of the method used to estimate the travel demand for the proposed non-conventional air transport services; section 4 deals with the technical characteristics of the types of helicopter and seaplane selected for the analysis; section 5 provides a cost analysis on the proposed nonconventional air transport services; section 6 illustrates the estimation of the generalized transport cost to reach the Eolie Islands from the airport of Catania, 
in relation to the existing and proposed modes of transport; finally in section 7 conclusions are drawn.

\section{Tourist demand and supply in the Eolie Islands}

The Eolie Archipelago is in the north-east of Sicily. It is composed of seven volcanic islands: Lipari, Salina, Vulcano, Alicudi, Filicudi, Stromboli and Panarea. Each of these has a different type of coastline; there are many beaches, caves and small islands. Most of the population live within the municipality of Lipari, which has 10,544 inhabitants.

According to data from the Department for Transport and Tourism of the Sicilian Region, the yearly flow of tourists arriving at the Eolie archipelago is about $9 \%$ of total tourist arrivals in the province of Messina and 2\% of tourists visiting Sicily. In 2008 arrivals of tourists in the province of Messina were $1,013,549$ versus 4,349,201 tourists visiting Sicily. Moreover the supply of accommodations at the Eolie archipelago consisted of 5,105 beds. About $67 \%$ of these were in hotels and the remaining 33\% were in other facilities. The ratio of available beds in all accommodation facilities to the population is 38.95 , which reveals the high degree of development of the Eolie Islands as tourist destination.

Data from the Local Agency for the Development of Tourism (2008) reveal that arrivals of visitors in the Eolie Archipelago increased from 90,000 to 116,000 in the period 1999-2008 (fig. 1). Arrivals showed a 4.3\% decrease in 2008 with respect to the previous year, which means about 5,000 units less (Figs. 1 and 2).

According to data from the Local Agency for the Development of Tourism (2008), presences of visitors in the Eolie Archipelago increased from 390,000 to 470,000 in the period 1999-2008 (Fig. 3). Presences showed a 3.4\% decrease in 2008 with respect to the previous year, which means about 16,000 presences less (Figs. 3 and 4).

Moreover, the seasonal pattern characterizing the time series of tourist flows changes depending on the journey origin (Fig. 5). So, in the case of foreign

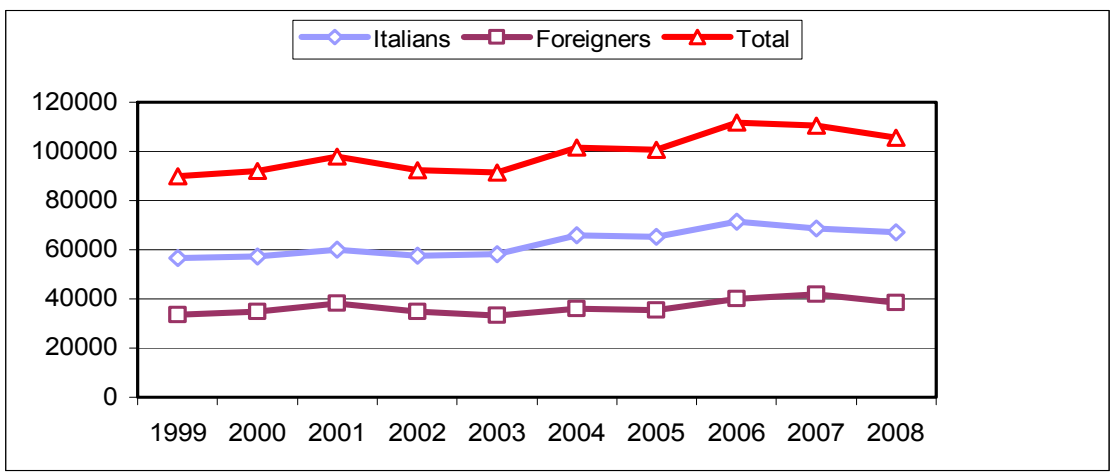

Figure 1: $\quad$ Time series of tourist arrivals in the Eolie Islands (1999-2008). 


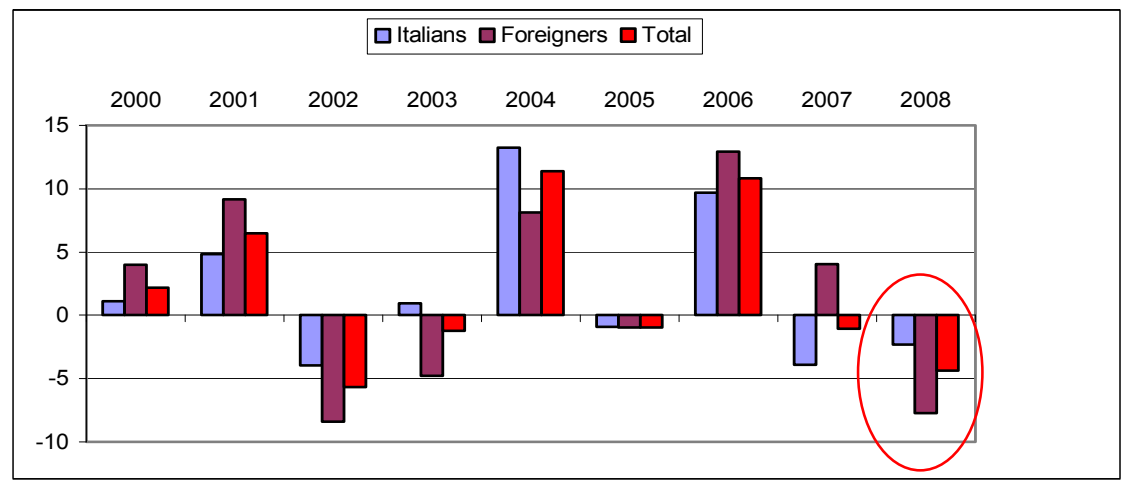

Figure 2: Percent variation of tourist annual arrivals with respect to the previous year (2000-2008).

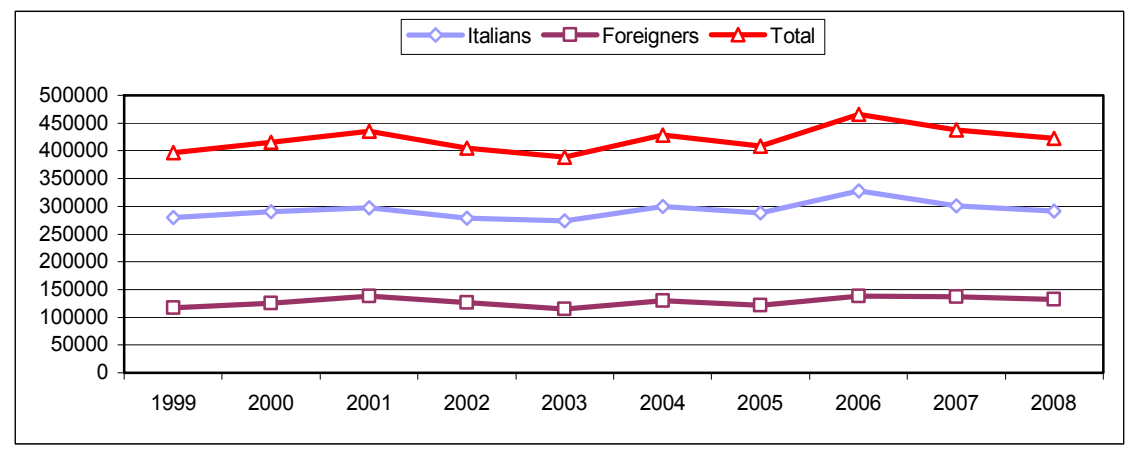

Figure 3: $\quad$ Time series of tourist presences in the Eolie Islands (1999-2008).

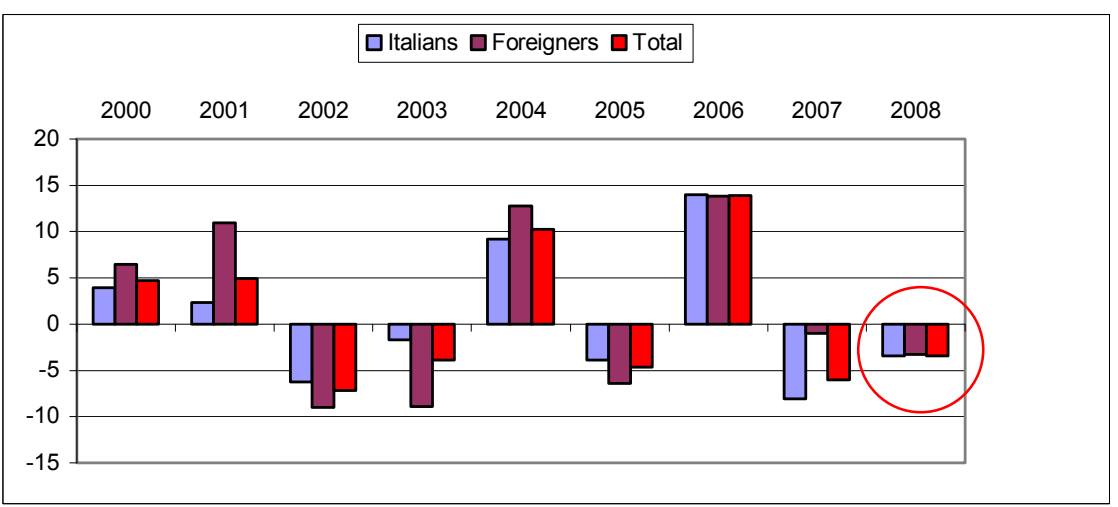

Figure 4: Percentage variation of tourist annual presence with respect to the previous year (2000-2008). 
visitors, both arrivals and presences are almost uniformly distributed in the April-October period. On the contrary, in the case of Italian tourists, flows fluctuate a lot over the year with a peak in the month of August.

In particular, the seasonal pattern characterizing the time series of tourist flows changes depending on the journey origin (Fig. 5). So, in the case of foreign visitors, both arrivals and presences are almost uniformly distributed in the April-October period. On the contrary, in the case of Italian tourists, flows fluctuate a lot over the year with a peak in the month of August.

Data regarding the selected category of accommodation show that about $85 \%$ of Italians stay in hotels and that about $38 \%$ of these prefer 3 and 4 -star hotels. Furthermore, about $88 \%$ of foreigners prefer hotels and approximately $42 \%$ of these stay in 3 and 4-star hotels.

Data concerning arrivals and presences of Italians and foreigners in the Eolie Archipelago demonstrate that the most visited island is Lipari, followed by Volcano, Stromboli and Panarea. The small islands of Alicudi and Filicudi attract a very low amount of tourists.

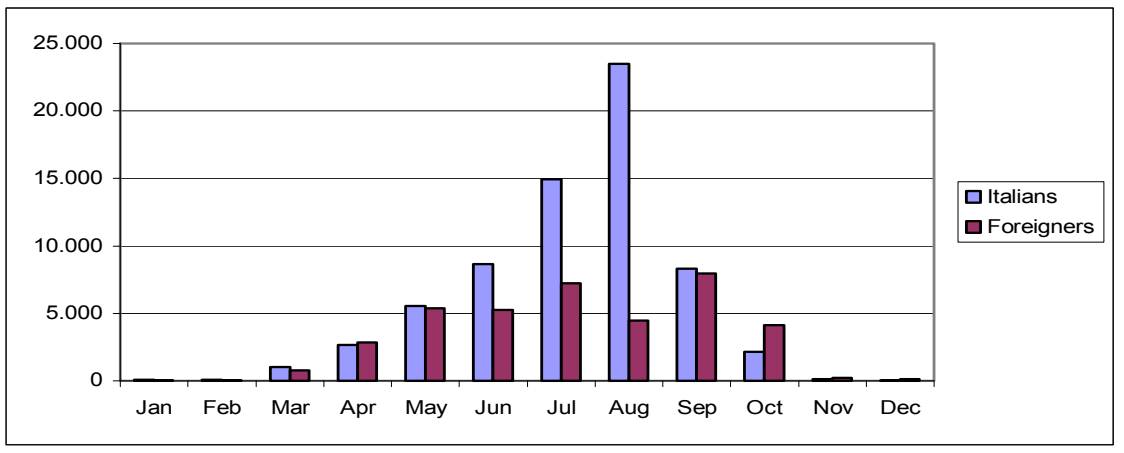

Figure 5: $\quad$ Seasonal pattern of tourist arrivals in 2008.

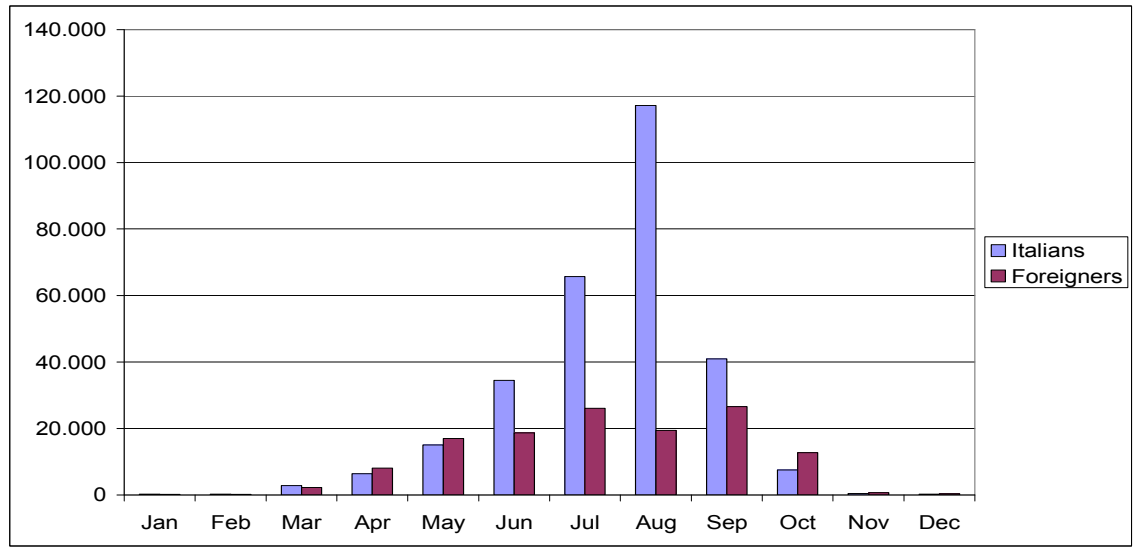

Figure 6: Seasonal pattern of tourist presence in 2008. 


\section{Forecasting the travel demand for non-conventional air transport}

The estimation of the potential travel demand for helicopter and seaplane transport services linking Sicily to the Eolie Islands was based on the time series of tourist arrivals (Italians and foreigners) in the period 1999-2008.

In particular, we didn't consider arrivals of Italian tourists from Calabria, Campania and Basilicata, since these regions are connected with the Eolie Islands by competitive maritime transport services. So, to get to one of the Eolie Islands, people coming from there don't have to reach Sicily by air and then use a combination of various modes of transport. Furthermore, we considered only visitors with a high willingness-to-pay for time savings (individuals choosing 3 and 4 star hotels) and we excluded a quota (20\%) of tourists not disposed to flying, determined on the basis of a previous study about air transport demand (Dean and Whitaker, [2]). We also considered as potential users of the proposed transport services a percentage of the Eolie Isles' population that was set according to data on the use of air transport by the Sicilian inhabitants (source: National Institute of Statistics and National Association of Airports). As in the case of other Sicilian minor islands, the use of air transport by the Eolie Islands' inhabitants could be favoured by a public financial support.

The resulting observations were employed to estimate an ARIMA model. In detail, we employed a monthly time series of tourist arrivals (Figure 7) that required first order non seasonal $(\mathrm{lag}=1)$ differencing to achieve stationary in mean, first order seasonal $(\mathrm{lag}=12)$ differencing to consider its seasonal pattern and natural log transformation to stabilize the amplitude of the seasonal changes.

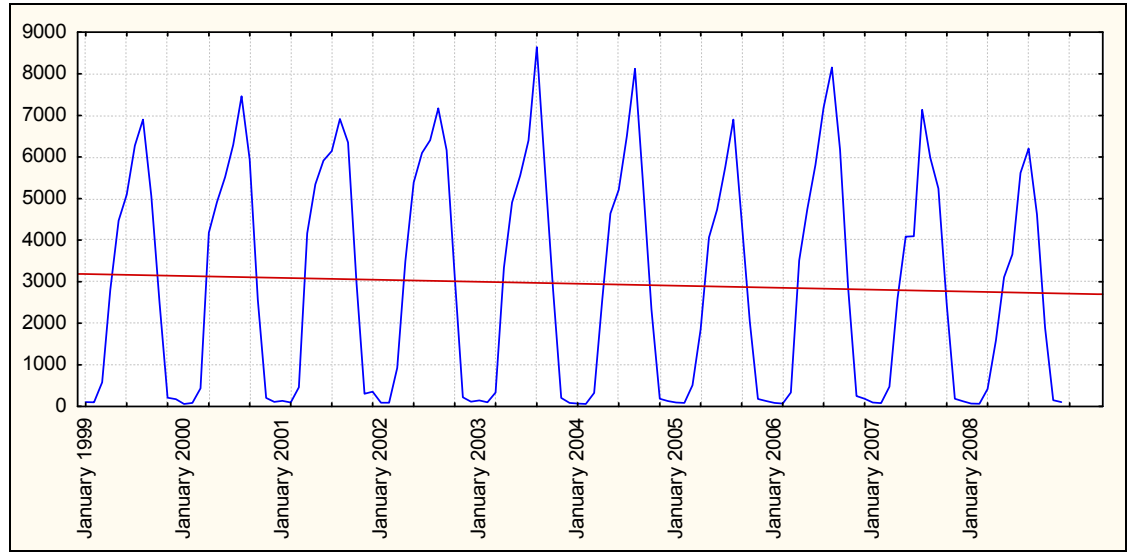

Figure 7: The monthly time series of tourist arrivals in the Eolie Islands for the 1999-2008 period. 
Based on the analysis of time series' correlograms of autocorrelation and a great deal of experimentation with alternative models, we estimated an ARIMA model (Box and Jenkins, [1]) with one regular moving average parameter and one seasonal moving average parameter and these parameters were computed for the series after it was differenced once with lag 1 , and once seasonally differenced. As can be observed in Table 1, the estimation of this ARIMA model led to highly statistically significant parameters; moreover, since these parameters are less than one, the model invertibility requirement is met.

To evaluate the goodness of fit, we can check how the two-parameter ARIMA predicts the observed cases and how its forecasts extend the observed series: Figure 8 shows that the estimated ARIMA model fits the time series very well and the observed values are within the confidence band of predicted values. Figure 9 displays the original series, forecasts for two full seasonal cycles following the last observed value and the related confidence limits.

Besides providing accurate forecasts, a reliable model should generate statistically independent and normally distributed residuals (difference between observations and predictions) that contain only noise and no systematic component (no autocorrelation), which means that the model is capable of "capturing" the underlying process producing the time series. Figure 10 reveals that the normal distribution fits the actual distribution of residuals well enough.

Table 1: Estimates of ARIMA parameters.

\begin{tabular}{|c|c|c|c|c|c|c|}
\hline & \multirow[b]{2}{*}{ Parameter } & \multirow{2}{*}{$\begin{array}{c}\text { Asymptotic } \\
\text { standard } \\
\text { error }\end{array}$} & \multirow{2}{*}{$\begin{array}{l}\text { Asymptotic } \\
\quad t(105)\end{array}$} & \multirow{2}{*}{$\begin{array}{c}P- \\
\text { value }\end{array}$} & \multicolumn{2}{|c|}{ Confidence Limit } \\
\hline & & & & & $\begin{array}{c}\text { Lower } \\
95 \%\end{array}$ & Upper 95\% \\
\hline$q(1)^{a}$ & 0.632 & 0.072 & 8.745 & 0.000 & 0.489 & 0.775 \\
\hline Qs(1) ${ }^{b}$ & 0.769 & 0.064 & 11.962 & 0.000 & 0.641 & 0.896 \\
\hline
\end{tabular}

${ }^{\mathrm{a}}$ regular moving average parameter.

${ }^{\mathrm{b}}$ seasonal moving average parameter.

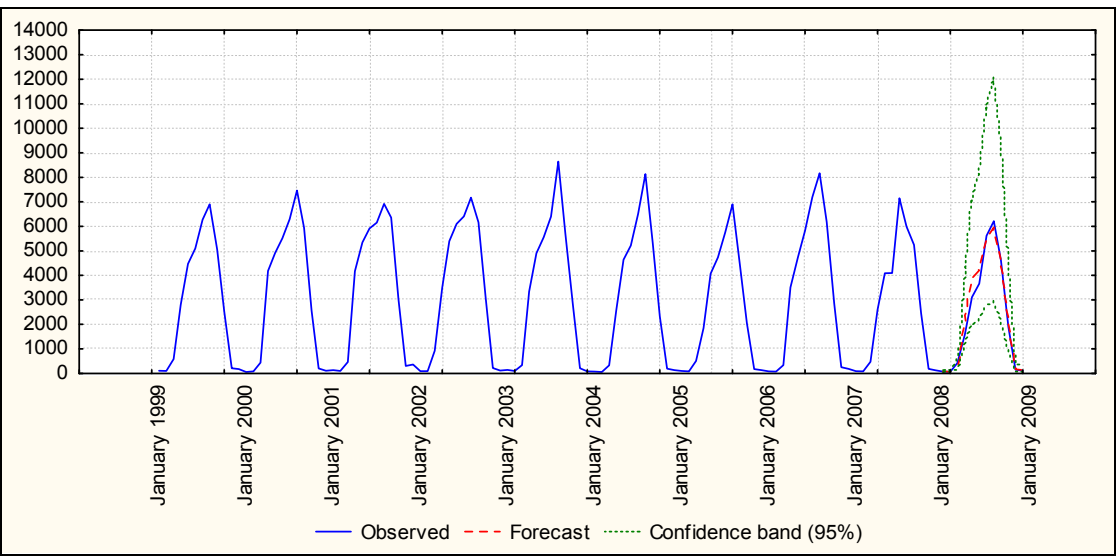

Figure 8: Comparison of ARIMA forecasts with observations. 


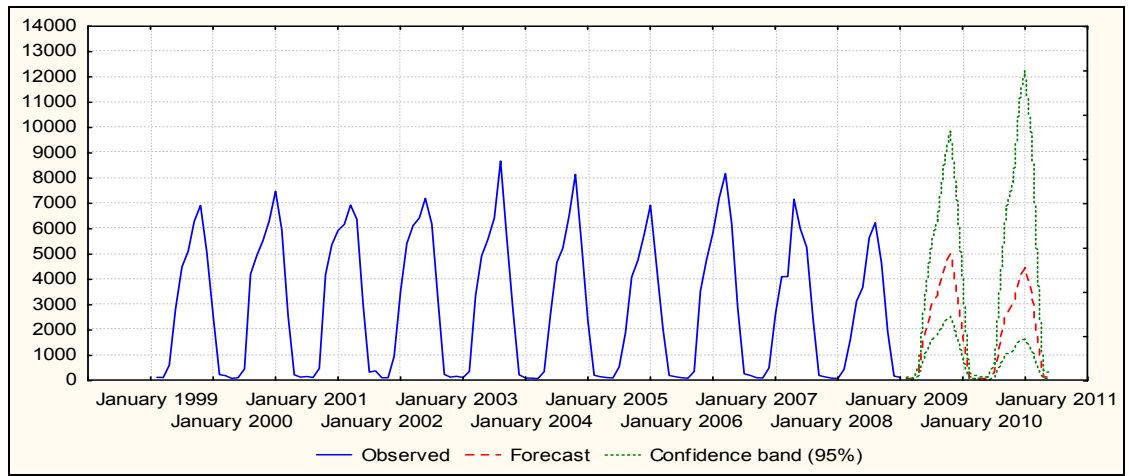

Figure 9: $\quad$ ARIMA forecasts for two full seasonal cycles.

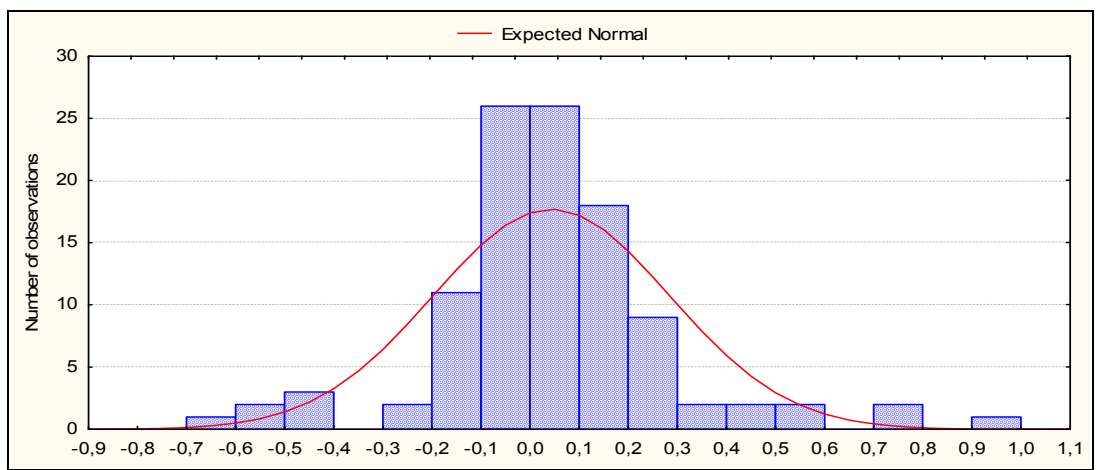

Figure 10: The actual distribution of residuals against the normal distribution.

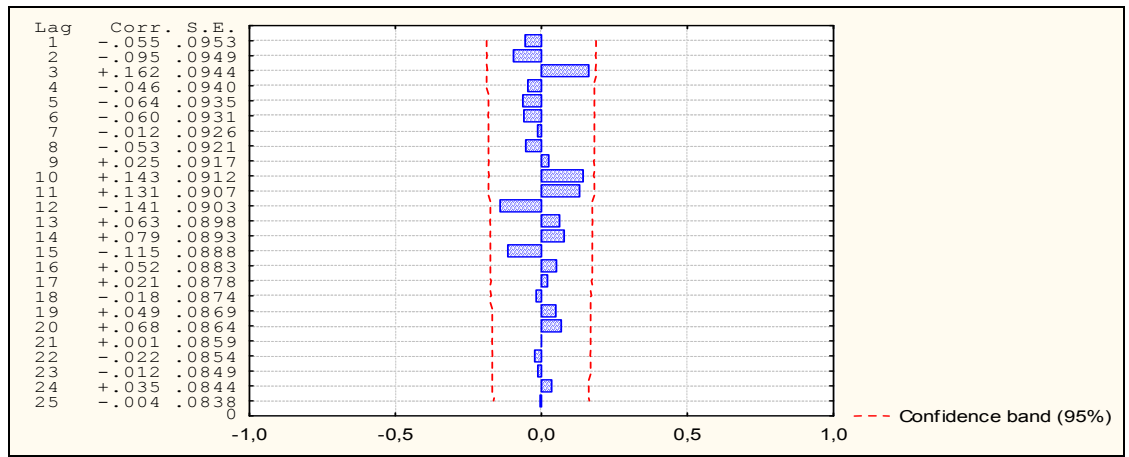

Figure 11: Correlogram graph displaying the autocorrelation function for the residuals. 


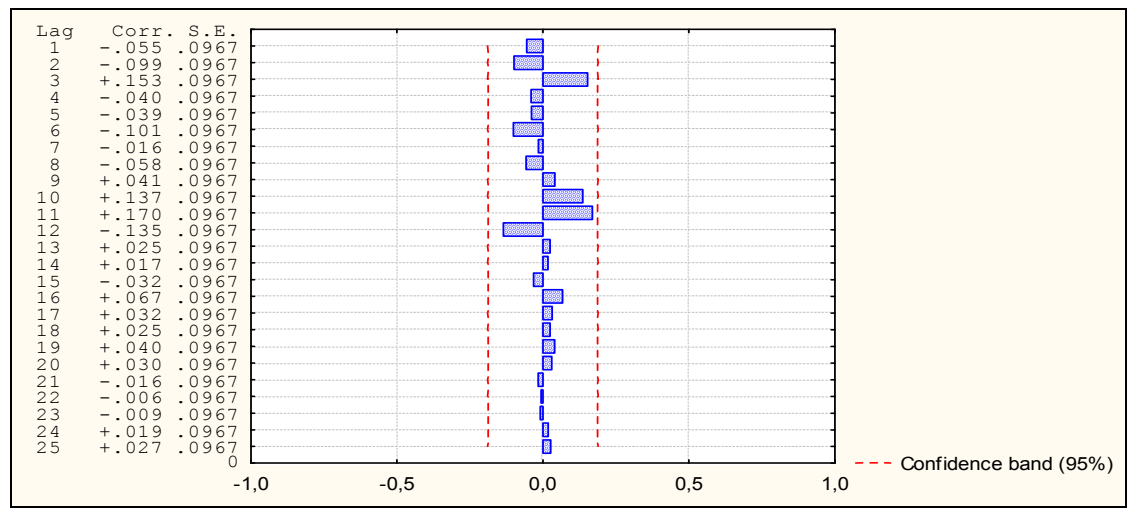

Figure 12: Correlogram graph displaying the partial autocorrelation function for the residuals.

To test whether the residuals are independent of each other, we can analyse their autocorrelation functions plotted in Figures 11 and 12. All the values of autocorrelation and partial autocorrelation estimated for lags of 1 to 15 are less than two times their standard errors (as indicated by the dotted line in the autocorrelation plots), which means that the residuals does not present any serial dependency.

\section{Selection of aircraft type for non-conventional regular air transport services}

As stated above, the objective of the research is to analyse the feasibility of scheduled transport services to connect the Sicilian airport of Catania to the Eolie Islands by helicopters with high capacity (12-14 seats) and seaplanes. This section details the selection of helicopter and seaplane types.

Based on a comparison among the most important producers of helicopters, we found out that the Agusta Westland AW139 and the Eurocopter AS365N3 are suitable for the proposed transport service.

The AW-139 is a medium sized helicopter constructed by Agusta Westland company that meets the rigorous safety standards required by civil and military aviation. Despite the reduced size (16.63 meters in length with rotors in motion), it can carry up to 15 passengers and it has a large baggage compartment compared to other helicopters of the same category. It is provided with the certification by the National Civil Aviation Agency (ENAC) for flying over towns in the day and night-time (Cat.A, Cl.1). It is equipped with two PRATT \& WHITNEY PT6C-67C motors; such an engine system along with the FADEC (Full Authority Digital Engine Control System) technology for the electronic engine control permit one to fly even in critical conditions (e.g. strong wind gusts, damages of one of the motors). Static flight is also possible with side winds of $45 \mathrm{Kts}$ (about $83 \mathrm{~km} / \mathrm{h}$ ). 
The AS365N3 is one of the first helicopters constructed by Eurocopter, a division of the European Aeronautical Defence and Space Company (EADS). It is a medium sized helicopter which can carry up to 12 passengers. Its fuselage and rotors are made of composite materials. Moreover, the AS365N3 is equipped with two Turbomeca Arriel 2C FADEC controlled engines and can operate with a ground wind of $55 \mathrm{Kts}$ (about $101 \mathrm{~km} / \mathrm{h}$ ). It is also provided with the Cat.A, Cl. 1 certification by ENAC.

Based on a worldwide analysis of producers of seaplanes, we identified the Viking Air (D)VHC6 and the Dornier Seawings Sea Star CD-2 as the most suitable seaplanes for the proposed transport service.

The (D)VHC-6 Twin Otter has been developed by Canadian (de Havilland) Viking Air. It is a fixed wing aircraft which can carry up to 20 passengers and is used in various fields: freight, passenger regional transport, skydiving and medevac (medical evacuation). The Twin Otter is equipped with two Pratt \& Whitney PT6A-27 turbo-propeller engines.

The Dornier Seawings Seastar is a novel turboprop-powered STOL aircraft developed by Canadian Claudius Dornier Seastar GmbH \& German Co KG Dornier GmbH. It is a "parasol" wing flying boat, with two Pratt \& Whitney PT6A-135A engines, which is largely made of composite materials and can carry up to 12 passengers.

Table 2: $\quad$ Technical features of the selected aircrafts.

\begin{tabular}{|c|c|c|c|c|}
\hline Helicopter/Seaplane & AW139 & AS365N3 & (D)VhC 6 400 & Seastar \\
\hline Empty Weight [kg] & 4,310 & 2,820 & 3,628 & 2,800 \\
\hline Maximum take-off weight [kg] & 6,400 & 3,800 & 5,670 & 4,594 \\
\hline Maximum useful load [kg] & 2,500 & 2,301 & 2,450 & 1,320 \\
\hline Payload [kg] & 1,350 & 1,080 & 1,710 & 1,080 \\
\hline Maximum number of passengers & 15 & 12 & 20 & 12 \\
\hline Fuel consumption per km [kg] & 2.39 & 2.29 & 2.93 & 4.02 \\
\hline Cruise speed [Kts] & 140 & 140 & 143 & 150 \\
\hline
\end{tabular}

\section{Analysis of non-conventional air transport services' costs}

This section focuses on the estimation of operational costs for the proposed nonconventional air transport services linking the Sicilian airport of Catania to Lipari, the most visited island of the Eolie Archipelago. The cost analysis referred to the types of helicopter and seaplane described above and based on the following data and assumptions: the distance between the main regional airport and Lipari is about $151 \mathrm{~km}$; the aircraft would fly with Visual Flight Rules (VFR) at a height of 2000 feet, with ISA+20 atmospheric conditions and in the day-time; each passenger weighs $75 \mathrm{~kg}$ while the weight of his baggage is $15 \mathrm{~kg}$.

Based on the data showed in Table 2, we calculated the travel time to go from the airport of Catania to the Island of Lipari with respect to the different nonconventional air transport alternatives, including additional times such as the time spent to buy the ticket, the time to get to the terminal, etc. 
Table 3: Total and average costs (Euros) of non-conventional air transport services to connect Sicily to the Eolie Islands.

\begin{tabular}{|c|c|c|c|c|}
\hline Helicopter/Seaplane & AW 139 & AS 365 N3 & (D)VhC 6 400 & Seastar \\
\hline Variable costs & $4,017,289$ & $4,178,296$ & $1,946,504$ & $1,863,743$ \\
\hline Fixed costs. & $2,087,493$ & $2,169,184$ & $1,731,864$ & $1,514,240$ \\
\hline Marketing costs $^{\text {a }}$ & 295,724 & 293,786 & 303,586 & 186,838 \\
\hline $\begin{array}{c}\text { Annual instalment of the loan taken out } \\
\text { to purchase two aircrafts }\end{array}$ & $1,758,458$ & $1,484,920$ & $1,641,227$ & 996,459 \\
\hline Total costs & $\mathbf{8 , 1 5 8 , 9 6 4}$ & $\mathbf{8 , 1 2 6 , 1 8 6}$ & $\mathbf{5 , 6 2 3 , 1 8 1}$ & $\mathbf{4 , 5 6 1 , 2 8 0}$ \\
\hline Average cost per trip & $1,422.4$ & $1,119.3$ & $1,316.9$ & 712 \\
\hline Average cost per passenger-trip & 101.6 & 93.3 & 69.3 & 593 \\
\hline
\end{tabular}

${ }^{a}$ Marketing costs are proportional to revenues.

${ }^{\mathrm{b}}$ We assumed a constant instalment loan with a fixed annual interest rate of $4.5 \%$.

Table 4: Hourly variable costs (Euros/hour) of non-conventional air transport services to connect Sicily to the Eolie Islands.

\begin{tabular}{|c|c|c|c|c|}
\hline Helicopter/seaplane & AW 139 & AS 365 N3 & (D)VhC 6 400 & Seastar \\
\hline Fuel $^{\text {a }}$ & 448 & 328 & 450 & 616 \\
\hline Lubricants $^{\text {Maintenance }}{ }^{\mathrm{b}}$ & 13 & 10 & 14 & 19 \\
\hline Supplies and catering & 660 & 460 & 151 & 95 \\
\hline Total variable costs per hour $^{\mathbf{1 , 0 2 7}}$ & $\mathbf{8 0 3}$ & $\mathbf{6 5 7}$ & 42 \\
\hline
\end{tabular}

${ }^{\mathrm{a}} \mathrm{We}$ considered a fuel cost of $0.92 € /$ litre.

${ }^{\mathrm{b}}$ Maintenance includes the following cost-drivers: labour, airframe, spare components, engine restoration, major periodic maintenance interventions.

Table 5: Annual fixed costs (Euros) of non-conventional air transport services to connect Sicily to the Eolie Islands.

\begin{tabular}{|c|c|c|c|c|}
\hline Helicopter/Seaplane & AW 139 & AS $365 \mathrm{~N} 3$ & (D) VhC 6400 & Seastar \\
\hline Crew salaries (captain and co-pilot) & 394,137 & 394,137 & 499,828 & 499,828 \\
\hline Land-side personnel & 98,534 & 98,534 & 124,957 & 124,957 \\
\hline Hangar (typical) & $1,000,000$ & $1,200,000$ & 500,000 & 500,000 \\
\hline Insurance (hull) ${ }^{\mathrm{c}}$ & 526,000 & 420,800 & 526,000 & 315,600 \\
\hline Admitted liability & 1,089 & 778 & 2,100 & 1,260 \\
\hline Legal liability & 16,533 & 16,533 & 8,500 & 8,500 \\
\hline Recurrent training & 18,206 & 8,480 & 13,400 & 13,400 \\
\hline Aircraft Modernization $^{\mathrm{d}}$ & 18,153 & 18,153 & 20,000 & 20,000 \\
\hline Navigation chart service & 299 & 299 & 2,059 & 2,059 \\
\hline Refurbishing & 12,286 & 9,214 & 31,920 & 25,536 \\
\hline Computer maintenance program & 1,712 & 1,712 & 2,400 & 2,400 \\
\hline Weather services & 545 & 545 & 700 & 700 \\
\hline Total fixed costs & $2,087,493$ & $2,169,184$ & $1,731,864$ & $1,514,240$ \\
\hline
\end{tabular}

${ }^{a}$ Including airport charges and hangar costs.

${ }^{\mathrm{b}}$ Crew salaries were estimated considering 2.5 crews per aircraft (each crew consisting of at least two pilots) and the Collective Agreement for helicopter and airline pilots in Italy.

c Insurance cost was estimated taking into account that one aircraft and an average of 5/12 of the second machine.

${ }^{\mathrm{d}}$ Aircraft modernization cost was appraised based on an average service life of 10 years. 
For the selected aircraft types, Table 3 shows the total and average costs of a scheduled service linking Sicily to the Eolie Islands. To calculate these, we considered variable and fixed costs based on the annual travel demand of 66,800 passengers, as forecasted by the ARIMA model in relation to the year 2010; the seasonal pattern characterizing such a demand led us to plan the use of one aircraft during the low season and two during the high season (5 months). Furthermore, we assumed a uniform distribution of trips during day-time. To perform a complete analysis, we also took into account marketing costs, namely those costs deriving from relations with advertising agencies and tour operators.

Tables 4 and 5 details the estimation of service variables and fixed costs, which were evaluated on the basis of a dataset from Concklin and de Decker [15].

\section{Estimation of the generalized transport cost to travel to the Eolie Islands when non-conventional air transport services are available}

This section deals with the computation of the generalized transport cost to travel from the Sicilian airport of Catania to Lipari, the most popular island of the Eolie Archipelago. In particular, we compared the multi-modal alternatives which are available at present with the helicopter and seaplane options. For the considered o-d pairs and the selected types of aircraft, the generalized transport cost per traveller was determined as the sum of three components: the monetary value of travel time, the external costs (namely social costs for air pollution, accidents, etc) and the service transport price.

The monetary value of travel time was estimated adopting the willingness-topay parameter (about 30 Euros/hour) provided by a previous study which developed a demand model for simulating the choice of tourists moving from Sicily to the Isle of Lipari between two modes of transport, hydrofoil and helicopter (Amoroso et al [14]).

The second component relating to external costs of transport was determined using the data form INFRAS/IWW [6] Table 6 presents the related estimates of external costs for the involved modes of transport in Euros per passenger-km.

As concerns the service transport price in the helicopter and seaplane case, on the basis of data in Table 3 we simulated two scenarios:

- the determination of fares so that revenues will balance costs;

- the determination of fares in order to make a profit equal to the annual instalment of the loan taken out to purchase the aircrafts.

Table 6: $\quad$ External costs (Euros/passenger- $\mathrm{km}$ ) per transport mode.

\begin{tabular}{|c|c|c|c|c|}
\hline Taxi & Bus & Train & Ferry & Helicopter/Seaplane \\
\hline 0.087 & 0.038 & 0.02 & 0.02 & 0.05 \\
\hline
\end{tabular}


Table 7: $\quad$ Fares of non-conventional air transport services to link Sicily to the Eolie Islands.

\begin{tabular}{|c|c|c|c|c|}
\hline \multirow{2}{*}{ Aircraft } & \multicolumn{2}{|c|}{ Revenues balance costs } & \multicolumn{2}{c|}{ Profit equal to the annual loan instalment } \\
\cline { 2 - 5 } & High season & Low season & High season & Low season \\
\hline AW139 & $€ 95.85$ & $€ 71.89$ & $€ 147.17$ & $€ 110.38$ \\
\hline AS365N3 & $€ 91.44$ & $€ 68.58$ & $€ 133.00$ & $€ 99.75$ \\
\hline (D)VhC 6 & $€ 54.40$ & $€ 40.80$ & $€ 103.74$ & $€ 77.80$ \\
\hline Seastar & $€ 36.05$ & $€ 27.03$ & $€ 64.53$ & $€ 48.39$ \\
\hline
\end{tabular}

Table 8: Annual budget* of non-conventional air transport services to link Sicily to the Eolie Islands.

\begin{tabular}{|c|c|c|c|c|c|c|c|c|}
\hline & \multicolumn{2}{|c|}{ AW-139 } & \multicolumn{2}{|c|}{ As365n3 } & \multicolumn{2}{|c|}{ (D)VhC 6400} & \multicolumn{2}{|c|}{ Seastar } \\
\hline & balance & profit & balance & profit & & profit & balance & profi \\
\hline \multicolumn{9}{|l|}{ Revenues } \\
\hline Low & 1,687 & 259 & 897 & 1,305 & 1,249 & 2,382 & 496 & 887 \\
\hline High se & 4,152 & 6,374 & 4,909 & 7,141 & 1,967 & 3,752 & 1,746 & 3,125 \\
\hline Tota & 8,088 & 11,214 & 8,057 & 10,696 & 5,466 & 8,383 & 4,492 & 6,263 \\
\hline \multicolumn{9}{|l|}{ Costs } \\
\hline Variable ar & 017 & 4,017 & 4,178 & 4,178 & 1,947 & 1,947 & 1,864 & 1,864 \\
\hline Fixed & 2,087 & 2,087 & 2,169 & 2,169 & 1,732 & 1,732 & 1,544 & 1,544 \\
\hline Com & 225 & 319 & 224 & 303 & 146 & 234 & 117 & 170 \\
\hline Tot & 6,329 & 6,423 & 6,572 & 6,650 & 3,825 & 3,912 & 3,495 & 3,548 \\
\hline OPE & 1,759 & 4,791 & 1,485 & 4,046 & 1,641 & 4,471 & 997 & 2,715 \\
\hline & 1,759 & 1,759 & 1,485 & 1,485 & 1,641 & 1,641 & 997 & 997 \\
\hline Profit b & 0 & 3,032 & 0 & 2,561 & 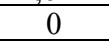 & 2,830 & 0 & 1,718 \\
\hline & 0 & 1,273 & 0 & 1,075 & 0 & 1,188 & 0 & 722 \\
\hline NET INCOME & 0 & 1,759 & 0 & 1,486 & $\mathbf{0}$ & 1,642 & $\mathbf{0}$ & 996 \\
\hline
\end{tabular}

${ }^{*}$ in thousands of Euros

For each of the selected aircrafts, Table 7 exhibits the low season and high season service fares under the two scenarios illustrated above, while Table 8 highlights the annual budget of the company providing the transport service.

We made a comparison between the proposed non-conventional air transport services and the following 4 combinations of transport modes that can be used at the present time to go from the airport of Catania to the Isle of Lipari:

1. Taxi (from the airport to Catania), Train (from Catania to Messina), Ferry (from Messina to Lipari);

2. Bus (from the airport to Catania), Train (from Catania to Messina), Ferry (from Messina to Lipari);

3. Bus (from the airport to Milazzo), Ferry (from Milazzo to Lipari);

4. Taxi or rental car (from the airport to Milazzo), Ferry (from Milazzo to Lipari).

Figures 10 and 11 show the results of the comparison mentioned above.

We found out that according to the generalized cost criterion, the helicopter is the best solution to connect the main Sicilian airport to the Eolie Isles. 


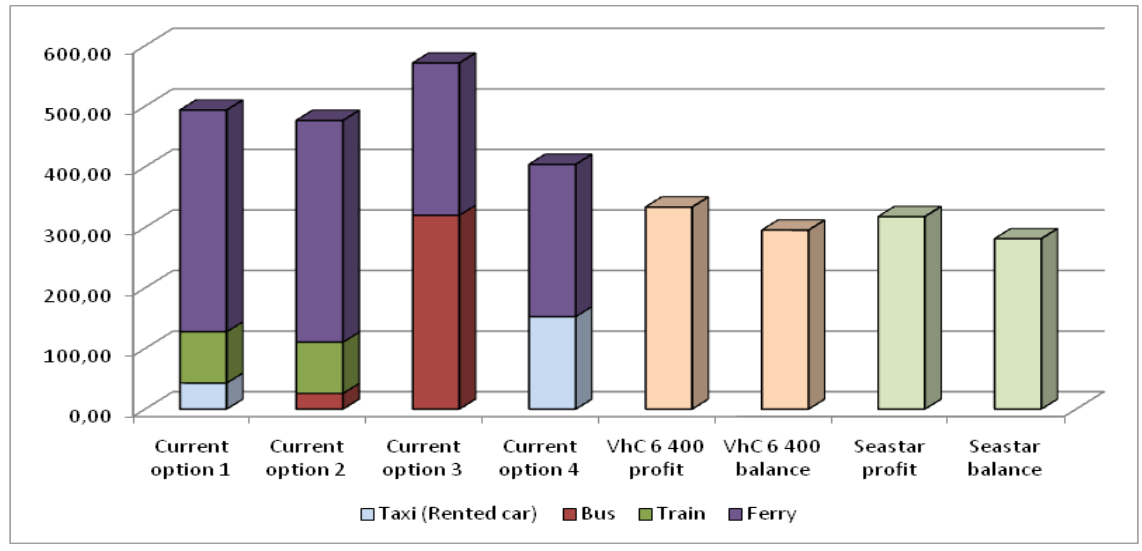

Figure 10: Estimation of the generalized transport cost to travel from Sicily to Lipari. Comparison between the current multimodal alternatives and the helicopter during high season.

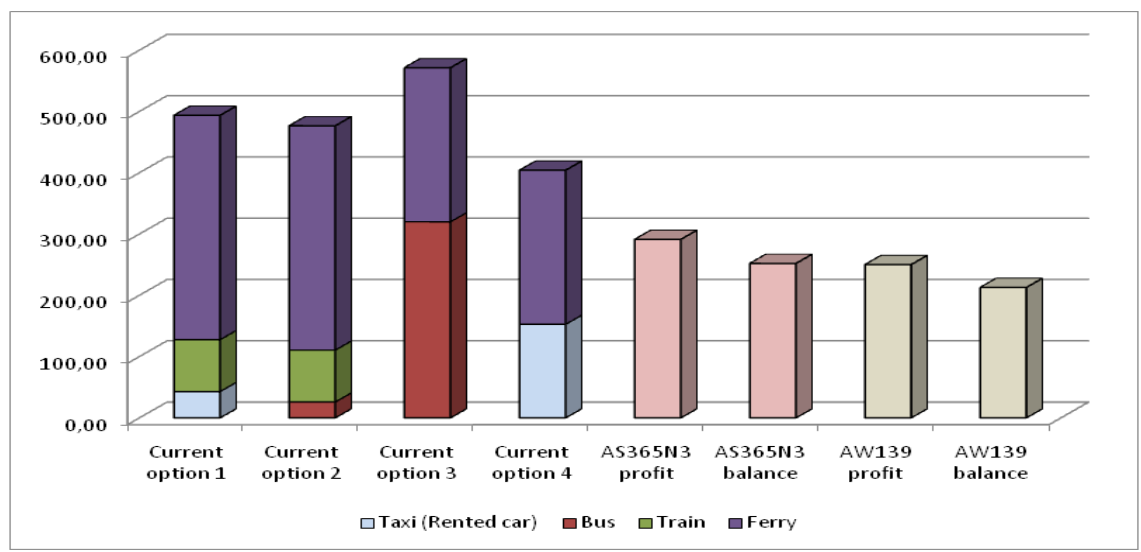

Figure 11: Estimation of the generalized transport cost to travel from Sicily to Lipari. Comparison between the current multimodal alternatives and the seaplane during high season.

\section{Conclusions}

This paper has demonstrated the feasibility of scheduled transport services using helicopter and seaplane for connecting Sicily, in the south of Italy, to the near and very attractive Eolie Islands.

To estimate the potential demand for such services, we referred to data on the arrivals of tourists in the Eolie Archipelago during the period 1999-2008. In detail, we considered only the market of visitors with a high willingness-to-pay for time savings (individuals choosing 3 and 4 star hotels) coming from origins at least $300 \mathrm{~km}$ away from the Eolie Islands; furthermore, we excluded $20 \%$ of 
these visitors to take into account the fear of flying. We also considered as potential users of the proposed transport services a percentage of the Eolie Isles' population. The resulting observations were employed to estimate forecasts through an ARIMA model.

After a technical analysis to identify the types of helicopter and seaplane suitable for regular transport services, based on the ARIMA model demand forecasts, we determined the service supply (daily frequency and number of aircrafts) in the different cases and evaluated the related total cost per passenger.

Next, we compared the helicopter and seaplane options with the various existing transport alternatives that can be used to reach the Eolie Islands from the major regional airport of Catania, according to the criterion of generalized transport cost (calculated by adding value of transit time, external costs and service fare). We found out that the helicopter is the best solution (in terms of generalized transport cost) to connect the main Sicilian airport to the Eolie Isles. What is more, it is important to underline that currently areas for helicopter takeoff and landing are available at the Eolie Isles and helicopter is less dependent on the weather conditions than seaplane which can't land with safety when the sea is stormy.

\section{References}

[1] Box, G. E. P. and Jenkins, G. M. (1976) "Time series analysis: Forecasting and control" San Francisco: Holden-Day

[2] Dean R.D. and Whitaker K.M. (1980) Fear of Flying, Impact on the U.S. Air Travel Industry, Boeing Company.

[3] Ortùzar, J. de D. and Willumsen, L. G. (1994) Modelling Transport. Chichester, England: Wiley.

[4] Mercury s.r.l., (2001) "Primo rapporto sul turismo in Sicilia"

[5] Assessorato del turismo delle Comunicazioni e dei Trasporti della Regione Sicilia (2001), "Piano Regionale dei Trasporti e della Mobilità".

[6] INFRAS/IWW (2004) External costs of transport: update study.

[7] Lupi, M. (2004) Metodi e modelli per la simulazione e verifica di un sistema di trasporto aereo: uno stato dell'arte, Edizioni Franco Angeli.

[8] Mercury s.r.1., (2005) "Rapporti sul turismo in Sicilia 2002-2003, 20032004"

[9] Parroco A.M., Vaccina F.M. (2005) "Isole Eolie quanto turismo?! Analisi dei mercati turistici regionali e sub-regionali", Edizioni CLEUP

[10] Ministero delle Infrastrutture e dei Trasporti - Quaderni del PON Trasporti N. 02. 2000-2006.

[11] Correnti V., Ignaccolo M., Inturri G. (2006) "Regional air transport in Europe: the potential role of the civil tiltrotor in reducing airside congestion", Journal of Air Transportation

[12] Correnti V., Santoro G., Inturri G. (2008) Il ruolo del tilt-rotor per lo sviluppo del trasporto aereo nell'area di libero scambio euromediterranea, Edizioni Offset Studio, Palermo, Italy 
[13] La Franca L., Castelluccio F. and Montano F. (2008) "Helicopter lines: demand \& cost analysis", Transportation decision making: issues, tools, models and case studies (International Conference - November 13th -14th), Venice, Italy

[14] Amoroso S., Migliore M., Catalano M. and Lo Casto B. (2009) "The demand of tourists for helicopter transport in areas with poor accessibility", 3rd IRT International Scientific Conference ("Integrated Relational Tourism-Territories and Development in the Mediterranean Area"), Il Cairo.

[15] Conklin \& de Decker (2009), Release Latest THE AIRCRAFT COST EVALUATOR Software Version 4.8.0. 